\title{
Chylomicron Remnant Clearance from the Plasma Is Normal in Familial Hypercholesterolemic Homozygotes with Defined Receptor Defects
}

\author{
David C. Rubinsztein," Jonathan C. Cohen, ${ }^{\ddagger}$ G. Michael Berger, ${ }^{5}$ Deneys R. van der Westhuyzen,* Gerhard A. Coetzee,* \\ and Wieland Gevers* \\ *The MRC/UCT Research Unit for Cell Biology of Atherosclerosis, Department of Medical Biochemistry, University of Cape Town, \\ South Africa; ${ }^{\ddagger}$ The Research Institute for Nutritional Diseases of the South African Medical Research Council, South Africa; and The \\ Department of Chemical Pathology, Red Cross War Memorial Childrens Hospital, South Africa
}

\begin{abstract}
The retinyl palmitate fat tolerance test was used to measure chylomicron remnant clearance in 10 normal subjects (apolipoprotein $E$ [apo E] isotypes 3 or 4 only), 6 normolipidemic apo E2/2 homozygotes and 5 familial hypercholesterolemic homozygotes. Skin fibroblasts with fully upregulated LDL receptors from the latter subjects degraded rabbit ${ }^{125} I-\beta V L D L$ in vitro at rates ranging from $<10-48 \%$ of normal. Experiments in vivo revealed no significant differences between the normal and homozygous familial hypercholesterolemic (FHH) subjects in chylomicron remnant clearance assessed on the basis of "areas under the curves" for retinyl palmitate levels present in postprandial serum, chylomicron remnants $(\mathrm{Sf} .<1,000)$, or chylomicrons (Sf. > 1,000). Remnant clearance was greatly decreased at all times in the apo E2/2 homozygotes, indicative of an important degree of flux control exerted by a receptor-mediated step involving apo $E$ as ligand. The absence of any excess remnant accumulation in FHH subjects with varying "impairment" of LDL receptor-mediated degradation of apo $E$ containing lipoproteins, permits the conclusion that chylomicron remnants are initially cleared from the plasma by apo E-recognizing receptors which are genetically distinct from LDL receptors. (J. Clin. Invest. 1990. 86:1306-1312.) Key words: chylomicron remnant - familial hypercholesterolemia • LDL receptor • vitamin $A \cdot$ retinyl palmitate $\bullet$ apolipoprotein E • apolipoprotein B
\end{abstract}

\section{Introduction}

An unresolved question in lipoprotein metabolism is the mechanism(s) by which chylomicron remnants are removed from the circulation (1). Apolipoprotein E (apo E) ${ }^{1}$ appears to serve as a ligand for receptor-mediated uptake of chylomicron remnants from the plasma (2-6), but the nature of the recep-

Address correspondence and reprint requests to Professor Wieland Gevers, Department of Medical Biochemistry, University of Cape Town Medical School, University of Cape Town, Observatory 7925, South Africa.

Received for publication 4 August 1989 and in revised form 17 May 1990.

1. Abbreviations used in this paper: Apo E, apolipoprotein E; CRP, chylomicron RP; FHH, homozygous familial hypercholesterolemia; PP, postprandial; RP, retinyl palmitate; RRP, remnant RP; SRP, serum RP; STG, serum triglycerides; WHHL, Watanabe heritable hyperlipidemic.

J. Clin. Invest.

(c) The American Society for Clinical Investigation, Inc.

$0021-9738 / 90 / 10 / 1306 / 07 \$ 2.00$

Volume 86, October 1990, 1306-1312 tor(s) remains uncertain. One possibility is that clearance of chylomicron remnants is mediated at the surfaces of parenchymal liver cells by apolipoprotein B, E (LDL) receptors coded for by a single allelic pair of genes on chromosome 19 (7). These receptors, which have been detected in liver cells from several species (8), have a high affinity for apo $\mathrm{E}$ and bind chylomicron remnants in vitro (9). In a recent study, rat chylomicron remnants and apo E-free LDL both bound to hepatic receptor molecules with a molecular weight similar to that of the LDL receptor; and $\sim 50 \%$ of the chylomicron remnant uptake in perfused rat livers was attributed to receptors that recognized both apo B100 and apo E (9). In support of this, Nagata et al. (10) found that an antibody to the LDL receptor markedly decreased the endocytosis of chylomicron remnants by isolated rat hepatocytes.

A cogent reason for questioning the involvement of apo B, $E$ receptors in chylomicron remnant clearance is provided by observations in genetic LDL receptor deficiency. Kita et al. (11) found that the removal of chylomicron remnants from the circulation, and their parallel accumulation in the liver, proceeded at a normal rate in Watanabe heritable hyperlipidemic (WHHL) rabbits, which suffer from homozygous LDL receptor gene mutations associated with a severe LDL receptor deficit. The authors proposed that rabbits express hepatic chylomicron-remnant receptors that are genetically distinct from the LDL receptor (11). Since chylomicron remnants have not been observed in the fasting plasma of patients with homozygous familial hypercholesterolemia (FHH), it has been suggested that humans also express a specific chylomicron-remnant receptor (12). These observations cannot be considered unequivocal evidence for an LDL receptor-independent pathway for chylomicron remnant clearance, however, as LDL receptor-mediated endocytosis of apo E-containing lipoproteins is catalyzed at significant rates by cultured fibroblasts from some FHH mutants (13), including WHHL rabbits (14).

One way of assessing the role of LDL receptors in the clearance of chylomicron remnants from the plasma is to study postprandial chylomicron metabolism in subjects with FHH, especially if the LDL receptor defects are defined with respect to the recognition and metabolism of apo E-containing ligands (1). The present study was accordingly undertaken to measure chylomicron remnant clearance in FHH subjects with varying degrees of LDL receptor insufficiency, in normolipidemic apo E2/2 homozygotes, and in normolipidemic, non-apo E2 controls. Since chylomicron remnant and $\beta$ VLDL clearance are both known to be mediated by apo E (15), $\beta$ VLDL degradation rates in cultured skin fibroblasts were used as an index of the capacity of hepatic LDL receptors in FHH subjects to mediate chylomicron remnant clearance. We used the retinyl palmitate (vitamin A) fat tolerance test (16) to measure the disappearance from the plasma of intestine-derived lipoproteins in vivo. This procedure is based on the ob- 
servation that dietary retinol is esterified in intestinal cells (mainly to retinyl palmitate [RP]), packaged in the chylomicron core (17), and retained in the chylomicrons and their remnants during lipolysis. The retinyl esters are taken up with the chylomicron remnants into the liver and are not resecreted in hepatic-derived lipoproteins in humans (18). Since there is little exchange of retinyl palmitate between intestine-derived and other circulating lipoproteins of normal individuals (19, 20), postprandial retinyl palmitate concentrations can be used to monitor chylomicron remnant clearance.

Our results indicate that the FHH subjects whose fibroblasts degraded apo E-bearing $\beta \mathrm{VLDL}$ at rates ranging from $<10$ to $\sim 50 \%$ of normal, clear chylomicron remnants at the same rate as do normal subjects, while the normolipidemic apo E2/2 homozygotes have grossly delayed clearance of these particles.

\section{Methods}

\section{Subjects}

Three groups of subjects were studied. (a) Five subjects (three men and two women) with FHH were recruited from the lipid clinic at Groote Schuur Hospital (Cape Town). These patients were diagnosed as FH homozygotes on the basis of the following criteria: $(i)$ positive family history of ischemic heart disease. (ii) Plasma cholesterol concentration $>580 \mathrm{mg} / \mathrm{dl}$ at presentation. (iii) Planar cutaneous xanthomata presenting within the first decade of life. (iv) Evidence of premature atherosclerosis. All patients have murmurs of aortic stenosis, and two have angina. (v) LDL receptor activity of $\leq 30 \%$ of normal in cultured fibroblasts (Table II).

The patients had all been treated with probucol and fortnightly plasma exchange. Three of these patients (S.A., R.I., and C.F.) stopped probucol treatment for $3 \mathbf{w k}$ before the study. Fat tolerance studies were performed at least $10 \mathrm{~d}$ after plasmapheresis. All patients had been advised to follow a low fat, low cholesterol $(\leq 200 \mathrm{mg} / \mathrm{d})$ diet.

Patient R.I. is homozygous for a mutation that results in the deletion of exons 7 and 8 from the EGF-precursor homology domain of the LDL receptor. This mutant receptor does not recognize LDL but binds to $\beta$ VLDL. Low levels of mutant receptors are expressed at the cell surface due to increased receptor degradation and a failure of occupied receptors to recycle (D. R. van der Westhuyzen et al., unpublished results).

Patient A.C. is homozygous for the LDL-receptor mutation most commonly found in Afrikaners (21) that is characterized by slow receptor processing, the expression of a relatively large number of receptors on the cell surface ( $\sim 60 \%$ of normal), and defective LDL binding $(\sim 20 \%$ of normal) (22).

Patients C.F., G.V., and S.A. are heteroallelic homozygotes. One of G.V.'s LDL-receptor alleles has the mutation found in A.C. and the other allele has a less common Afrikaner mutation (21). Patient C.F. has the A.C. mutant allele and an allele with an unknown mutation. Patient S.A. has two other mutations that are as yet uncharacterized (unpublished results).

(b) Six normolipidemic subjects (four men and two women) homozygous for the apo E2/2 isoform (E2/2) were recruited by screening relatives of type III hyperlipoproteinemic probands. None of these subjects used any medication.

(c) 10 normolipidemic volunteers (four men and six women) who were of similar age and anthropometry to the FHH patients, and who did not have the apo E2 isoform (normals) were recruited. These subjects were healthy and used no medication including oral contraceptives. None of the normolipidemic subjects smoked or took regular vigorous exercise.

Fat tolerance tests. All studies were conducted on an outpatient basis. The subjects reported to the laboratory at 8:00 am after an overnight fast. Each person received a standard meal consisting of 100 $\mathrm{ml}$ dairy cream $(40 \%$ fat $\mathrm{wt} / \mathrm{vol}), 100 \mathrm{ml}$ water, $3 \mathrm{~g}$ chocolate flavouring, and 50,000 U vitamin A palmitate (Arovit; Roche Products, Isando, South Africa). Blood samples drawn before and at 1.5, 2.5, 3.5, 5 , and $7 \mathrm{~h}$ after the meal were allowed to clot and serum was collected by centrifugation. 1-ml aliquots (for plasma triglyceride and retinyl palmitate determinations) were wrapped in aluminum foil and stored at $-20^{\circ} \mathrm{C}$. Aliquots for density gradient ultracentrifugation were mixed with $\operatorname{EDTA}(1.2 \mathrm{mg} / \mathrm{ml})$ and stored at $4^{\circ} \mathrm{C}$.

\section{Lipoprotein analyses}

Ultracentrifugation. Since the demarcation between chylomicrons and their remnants has not been precisely defined, nominal separation of these fractions was effected by rate flotation using the criteria defined by Grundy and Mok (23) and adopted by others (24). Aliquots $(2 \mathrm{ml})$ of all postprandial samples were underlayered under $9 \mathrm{ml}$ saline $(d$ $=1.006 \mathrm{~g} / \mathrm{ml}$ ) and centrifuged at $8.5 \times 10^{9} \mathrm{radians}^{2} / \mathrm{s}$ in a Beckman SW40 rotor (Beckman Instruments Inc., Fullerton, CA). Lipoproteins of Sf $>1,000(1 \mathrm{ml})$ were aspirated from the surface of the tube. This fraction was designated chylomicrons. Lipoproteins harvested in this manner from normal subjects and from normolipidemic E2/2 subjects produced a single nonmigrating band when subjected to lipoprotein electrophoresis (as described below). This band was not observed in the Sf $<1,000$ lipoproteins which were considered to be remnants (data not shown).

To further characterize the plasma distribution of retinyl palmitate, samples drawn at $0,2.5$, and $7 \mathrm{~h}$ from four FHH patients, three E2/2 subjects, and three normal subjects were subjected to discontinuous density gradient ultracentrifugation. $2.7 \mathrm{ml}$ serum was mixed with 1.3 $\mathrm{g}$ potassium bromide and then successively overlayered with $5.2 \mathrm{ml}$ of a $\mathrm{KBr}$ solution of $d=1.25 \mathrm{~g} / \mathrm{ml}$ and $9.2 \mathrm{ml}$ of a $0.05 \mathrm{M} \mathrm{NaCl}$ solution containing $0.1 \mathrm{mM} \mathrm{NaN}_{3}$ and $0.1 \mathrm{mM}$ EDTA. Samples were centrifuged for $23 \mathrm{~h}$ at $28,000 \mathrm{rpm}$ in a Beckman SW28 rotor at $20^{\circ} \mathrm{C}$ (Beckman Instruments Inc.). The contents of the tubes were collected by introducing a dense $(d=1.35 \mathrm{~g} / \mathrm{ml})$ solution into the bottom of the tubes and by pumping the contents through an ultraviolet monitor $(280 \mathrm{~nm})$. Aliquots of $0.45 \mathrm{ml}$ were collected using a fractionator (Isco Inc., Lincoln, NE) and stored at $-20^{\circ} \mathrm{C}$.

Lipoprotein electrophoresis. Agarose electrophoresis using commercially prepared gels (Paragon system; Beckman Instruments Inc.) was performed on fasting samples and on samples drawn at 2.5 and $7 \mathrm{~h}$.

Retinyl palmitate assay. Retinyl esters were extracted from serum and ultracentrifugal fractions with ethanol, water, and hexane $(8: 8: 16$ vol/vol/vol) and separated by reverse-phase HPLC using a C-18 column (Novapak; Waters Associates, Milford, MA). Methanol ( $2 \mathrm{ml} /$ $\mathrm{min}$ ) was the mobile phase. The ultraviolet absorption of the column effluent was monitored at $326 \mathrm{~nm}$. Peaks were identified by comparison with purified standards. Retinol, retinyl palmitate, stearoyl chloride, and undecanoyl chloride were purchased from Sigma Chemical Co. (St. Louis, MO). Retinyl undecanoate and retinyl stearate were synthesized from retinol and the corresponding acyl chlorides as described by Huang and Goodman (25). All esters were repurified by preparative HPLC and their purity (> 96\%) was determined by spectral analysis on a diode array detector.

Lipid assays. Serum and chylomicron triglyceride concentrations, and serum cholesterol concentrations were determined enzymatically using commercial kits (Boehringer Mannheim, Mannheim, FRG). The assays were standardized with a lyophilized plasma standard (Precilip; Boehringer Mannheim).

Apolipoprotein E phenotyping. Plasma samples for apo E phenotyping were treated with dithiothreitol $(0.01 \mathrm{mmol} / \mathrm{ml})$, after which lipoproteins of density $<1.019 \mathrm{~g} / \mathrm{ml}$ were isolated by ultracentrifugation in a Beckman SW28 rotor (Beckman Instruments, Inc.). The $d$ $<1.019$ lipoprotein factions were delipidated with isopropanol and the supernatants dialyzed against $0.15 \mathrm{M} \mathrm{NaCl}, 1 \mathrm{mM} \mathrm{NaN}_{3}$, and $1 \mathrm{mM}$ EDTA, pH 7.4. Apo E phenotypes were determined by two-dimensional electrophoresis using the Iso-Dalt system (26). The first dimension isoelectric focusing was run in tube gels containing $0.25 \mathrm{~g}$ urea, 6.2 
$\mathrm{ml} \mathrm{H}_{2} \mathrm{O}, 1.8 \mathrm{ml}$ of $30 \%$ acrylamide with $1.8 \%$ bisacrylamide, $0.5 \%$ ampholines of $\mathrm{pH} 3-10$, and $1.5 \%$ ampholines of $\mathrm{pH} 4-6$. The second dimension was run on a $15 \%$ acrylamide SDS gel and the separated proteins stained with Coomassie blue. Spots corresponding to the apo $\mathrm{E}$ isoforms were identified by comparison with known apo $\mathrm{E}$ phenotypes.

Degradation of ${ }^{125} I-L D L$ and ${ }^{125} I-\beta V L D L$ in cultured fibroblasts. Human LDL (27) and rabbit $\beta$ VLDL (28) were prepared and iodinated as described previously. Fibroblasts were seeded in Dulbecco's modified essential medium containing $10 \%$ fetal calf serum at a density of 3 $\times 10^{4}$ cells per $60 \mathrm{~mm}$ dish. Medium was changed on $\mathrm{d} 3$. After $5 \mathrm{~d}$ the medium was replaced with medium containing lipoprotein-deficient serum $(2.5 \mathrm{mg}$ protein $/ \mathrm{ml})$. On d 6 the medium was replaced with a fresh aliquot of the same medium. On $d 7$, duplicate dishes each received $2 \mathrm{ml}$ of medium containing lipoprotein-deficient serum plus either (a) $10 \mu \mathrm{g}$ protein/ml ${ }^{125} \mathrm{I}-\mathrm{LDL}(274 \mathrm{cpm} / \mathrm{ng}$ protein), $(b) 10 \mu \mathrm{g}$ protein $/ \mathrm{ml}{ }^{125} \mathrm{I}-\beta$ VLDL $\left(771 \mathrm{cpm} / \mathrm{ng}\right.$ protein), or $(c){ }^{125} \mathrm{I}-\beta \mathrm{VLDL}$ at varying concentrations of $0.4-12.0 \mu \mathrm{g}$ protein $/ \mathrm{ml}$. Nonspecific degradation of ligands in experiments 1 and 2 was assessed by analyzing the degradation of iodinated ligands in the presence of $200 \mu \mathrm{g}$ protein $/ \mathrm{ml}$ of unlabeled LDL and $100 \mu \mathrm{g}$ protein/ml of unlabeled $\beta$ VLDL. After incubation for $4 \mathrm{~h}$ at $37^{\circ} \mathrm{C}$, the medium was removed, and its content of noniodide trichloroacetic acid-soluble radioactivity was measured (29). In experiments 1 and 2, receptor-mediated degradation was calculated from the difference between values obtained in the absence and in the presence of unlabeled ligands. In experiment 3 , the maximum degradation rates of $\beta \mathrm{VLDL}$, and the concentrations of $\beta \mathrm{VLDL}$ that yielded half of the maximum degradation rate were calculated using a commercial curve-fitting program (Enzfitter; Elsevier Biosoft, Cambridge, UK), assuming one specific site plus nonspecific processes.

Statistical evaluation of results. Postprandial serum triglyceridemia (PP-STG) in each subject was calculated from the area between the curve described by serum triglyceride concentration plotted against time, and the line originating at the zero-time point drawn parallel to the abscissa. The postprandial retinyl palmitate concentrations in serum (PP-SRP), chylomicron (PP-CRP), and remnant (PP-RRP) fractions in each subject were calculated using the same method. The mean values of these parameters in the three groups were compared using unpaired $t$ tests. Probability values were adjusted for replicate analysis using Bonferroni's procedure.

\section{Results}

The clinical features of the FHH patients, the normolipidemic E2/2 subjects, and the normal controls are summarized in Table I. All individuals were normotriglyceridemic (fasting triglyceride $<200 \mathrm{mg} / \mathrm{dl}$ ) and none of the E2/2 or normal subjects were hypercholesterolemic (total cholesterol $<250$ $\mathrm{mg} / \mathrm{dl}$ ). Lipoprotein electrophoresis clearly indicated broad beta bands (representing chylomicron and VLDL remnants) in fasting samples from five of the six E2/2 subjects but not in any of the normal or the FHH subjects (data not shown). This observation was supported by ultraviolet absorption profiles of lipoprotein fractions from fasting samples subjected to density gradient centrifugation, which revealed extensive accumulation of IDL particles in E2/2 subjects, but not in the FHH subjects or in the normal controls (data not shown).

The fat meal was well tolerated by all subjects and none developed nausea or diarrhea. At each time point, the mean serum retinyl palmitate concentration was considerably higher in the E2/2 subjects than in the subjects of the other two groups (Fig. 1). The mean "area under the curve" for PP-SRP in the E2/2 group was markedly higher than in the other groups $(P<0.001)$ but was similar in normal and in FHH patients (Table I). During the first half of the test period, the shape of the serum retinyl palmitate curve was similar in normal and in FHH subjects (Fig. 1). $7 \mathrm{~h}$ after the meal, however, serum retinyl palmitate concentrations were higher in $\mathrm{FHH}$ patients than in the normal subjects (see below).

In all groups, most of the retinyl palmitate was present in the remnant fraction (Table I). The mean "area under the curve" value for PP-RRP in the FHH subjects was not significantly higher than that for the normal subjects (Table I and Fig. 2) but was markedly greater in the apo E2/2 subjects. Density gradient ultracentrifugation indicated that normal subjects (measured at 2.5 and $7 \mathrm{~h}$ ) accumulated RP primarily in the least dense lipoproteins (corresponding to the initially collected fractions in the density range of fasting VLDL), whereas in E2/2 subjects RP was equally distributed throughout the VLDL and the IDL ranges (data not shown). Less than $5 \%$ of the serum RP from each of the normal subjects was recovered in the LDL fraction at all time points, while $\mathrm{FHH}$ patients showed a progressive accumulation of RP in the LDL fraction. In samples drawn $2.5 \mathrm{~h}$ after the meal, RP distribution was similar in FHH and in normal subjects, but $7 \mathrm{~h}$ after the meal, an average of $40 \%$ of the serum RP in the FHH subjects was carried in the LDL fraction. At this time, neither the normal nor the FHH subjects exhibited the large populations of VLDL- and IDL-sized chylomicron remnants that were evident in the density gradient studies of the E2/2 subjects (data not shown).

Lipoprotein electrophoresis. Fat feeding in the case of both the normal and the FHH subjects did not give rise to broad beta bands such as were present even in the fasting state in the apo E2/2 homozygotes (data not shown).

Serum triglycerides (PP-STG). Serum triglyceride concentrations increased promptly after the meal in each group of subjects (Fig. 3). The magnitude of postprandial triglyceridemia was not significantly different in any of the groups (Table II).

Degradation of ${ }^{125} I-L D L$ and ${ }^{125} I-\beta V L D L$ by cultured fibroblasts. The rates of degradation of ${ }^{125} \mathrm{I}-\mathrm{LDL}$ and ${ }^{125} \mathrm{I}-\beta$ VLDL by cultured fibroblasts from $\mathrm{FHH}$ patients in three separate experiments are shown in Table II. Maximum ${ }^{125} \mathrm{I}-\beta \mathrm{VLDL}$ degradation rates were reduced in all the $\mathrm{FHH}$ subjects and showed a wide variation in activity from $\sim 50$ to $<10 \%$ of normal. Maximum ${ }^{125}$ I-LDL degradation rates followed the same trend as the ${ }^{125} \mathrm{I}-\beta \mathrm{VLDL}$ degradation rates (A.C. > S.A. > G.V. > R.I. and C.F.), ranging from $\sim 30$ (A.C.) to $<1 \%$ of normal (R.I.). There was no correlation between either the PP-RRP (Fig. 4) or PP-SRP values of the individual FHH subjects and the in vitro $\beta$ VLDL (or LDL) degradation rates.

\section{Discussion}

The clearance of chylomicron remnants from the plasma was not impaired in subjects with FHH. Postprandial retinyl palmitate concentrations in whole serum and in the remnant fraction were similar in normal and in the FHH subjects. Analysis of postprandial lipoproteins, by electrophoresis and by density gradient ultracentrifugation, revealed no abnormal accumulation of IDL-sized lipoproteins in the FHH subjects in the period where triglycerides were being absorbed.

The postprandial concentrations of RP in circulating lipoproteins reflect both absorptive and clearance processes, and it is accordingly possible that impaired chylomicron remnant 
Table I. Clinical Features and Retinyl Palmitate Responses to Vitamin A Fat Tolerance Tests in FHH Patients, Normolipidemic Apolipoprotein E2/2 Homozygotes (E2/2), and Normal (Non-E2) Subjects

\begin{tabular}{|c|c|c|c|c|c|c|c|c|c|}
\hline Subject & Age & Height & Mass & $\begin{array}{l}\text { Total fasting } \\
\text { serum } \\
\text { cholesterol } \\
\text { concentrat. }\end{array}$ & $\begin{array}{c}\text { Apo E } \\
\text { phenotype }\end{array}$ & PP-SRP* & PP-CRP* & PP-RRP* & PP-STG* \\
\hline & $y$ & $\mathrm{~cm}$ & $k g$ & $m M / l i t e r$ & & & $n g / m l / 7 h$ & & $m g / d l / 7 h$ \\
\hline \multicolumn{10}{|l|}{ Normals } \\
\hline N.W. & 16 & 171 & 63 & 4.2 & $3 / 3$ & 2,526 & 462 & 2,064 & 39 \\
\hline M.L. & 17 & 155 & 45 & 5.1 & $3 / 3$ & 7,930 & 1,185 & 6,746 & 403 \\
\hline D.H. & 17 & 182 & 71 & 4.1 & $3 / 3$ & 2,037 & 361 & 1,676 & 171 \\
\hline D.R. & 17 & 168 & 55 & 4.0 & $3 / 3$ & 1,831 & 686 & 1,145 & 190 \\
\hline K.A.H. & 16 & 162 & 59 & 4.0 & $3 / 4$ & 4,436 & 1,437 & 2,999 & 185 \\
\hline I.F. & 16 & 171 & 58 & 4.5 & $3 / 3$ & 2,834 & 504 & 2,330 & 109 \\
\hline R.F. & 15 & 168 & 58 & 3.6 & $3 / 4$ & 2,640 & 824 & 1,816 & 204 \\
\hline C.R. & 16 & 170 & 58 & 5.0 & $3 / 3$ & 2,952 & 1,764 & 1,188 & 260 \\
\hline L.S. & 17 & 171 & 80 & 5.0 & $3 / 3$ & 3,932 & 338 & 2,594 & 64 \\
\hline M.L. & 22 & 184 & 91 & 4.4 & $3 / 3$ & 4,917 & 600 & 4,317 & 90 \\
\hline Mean & 17 & 170 & 64 & 4.4 & & 3,504 & 816 & 2,688 & $172 \S$ \\
\hline SD & 2 & 8 & 13 & 0.5 & & 1,831 & 488 & 1,705 & 107 \\
\hline \multicolumn{10}{|c|}{ Normolipidemic E2/2 homozygotes } \\
\hline K.H. & 20 & 172 & 62 & 4.8 & $2 / 2$ & 26,449 & 5,250 & 19,419 & 590 \\
\hline G.H. & 32 & 168 & 52 & 4.0 & $2 / 2$ & 6,484 & ND & ND & 23 \\
\hline P.M. & 30 & 170 & 80 & 4.2 & $2 / 2$ & 17,042 & 1,957 & 15,086 & 10 \\
\hline M.J. & 44 & 150 & 79 & 5.8 & $2 / 2$ & 8,414 & 986 & 7,428 & 103 \\
\hline E.M. & 39 & 158 & 69 & 4.6 & $2 / 2$ & 9,858 & 1,465 & 8,393 & 168 \\
\hline Z.F. & 19 & 164 & 53 & 2.5 & $2 / 2$ & 6,629 & 750 & 5,878 & 57 \\
\hline Mean & 31 & 164 & 66 & 4.3 & & $12,183 \ddagger$ & 2,082 & $11,241 \ddagger$ & 159 \\
\hline SD & 10 & 8 & 12 & 1.1 & & 7,245 & 1,831 & 5,768 & 219 \\
\hline \multicolumn{10}{|c|}{ Homozygous familial hypercholesterolemic subjects } \\
\hline S.A. & 15 & 171 & 61 & 14 & $3 / 3$ & 3,884 & 668 & 3,217 & 37 \\
\hline R.I. & 18 & 160 & 54 & 15 & $3 / 4$ & 4,171 & 999 & 3,172 & 72 \\
\hline C.F. & 12 & 151 & 36 & 12 & $3 / 3$ & 3,788 & 1,496 & 2,292 & 199 \\
\hline A.C. & 18 & 174 & 69 & 14 & $3 / 3$ & 5,208 & 780 & 4,428 & 81 \\
\hline G.V. & 26 & 165 & 84 & 16 & $4 / 4$ & 4,530 & 236 & 4,294 & 132 \\
\hline Mean & 18 & 164 & 61 & 14.2 & & 4,316 & 836 & 3,481 & $104 \S$ \\
\hline D & 5 & 9 & 18 & 1.5 & & 576 & 462 & 886 & 63 \\
\hline
\end{tabular}

* PP-SRP, PP-CRP, PP-RRP, and PP-STG represent the "area under the curves" for the postprandial serum retinyl palmitate, chylomicron retinyl palmitate, remnant retinyl palmitate, and serum triglyceride concentrations, respectively; $¥ P<0.005$ (compared to the normal value using an unpaired $t$ test); $\S P=0.2207$, not significant; and ND, not done.

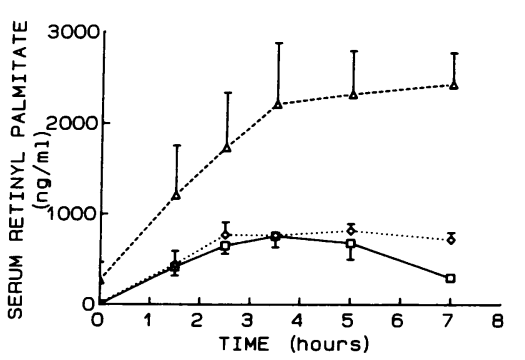

Figure 1. Serum retinyl palmitate concentration curves. Total serum retinyl palmitate responses were assessed in 10 normolipidemic subjects not expressing Apo E2 (squares), 6 normolipidemic Apo E2/2 homozygotes (triangles), and 5 familial hyper-

cholesterolemic homozygotes (diamonds) after a 40-g fat meal with $50,000 \mathrm{U}$ vitamin A. For each group the levels at each time point were averaged. Bars represent the standard errors of the means.

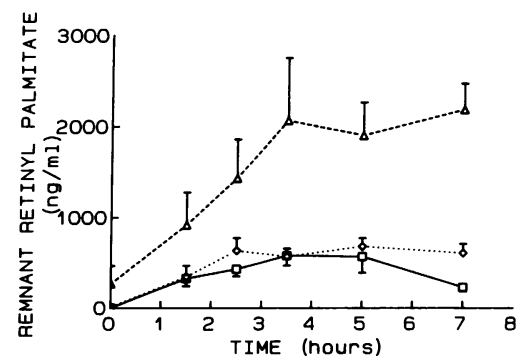

Figure 2. Remnant retinyl palmitate concentration curves. Remnant $(\mathbf{S f}<1,000)$ retinyl palmitate responses were determined in 10 normolipidemic subjects not expressing Apo E2 (squares), 6 normolipidemic Apo E2/2 homozygotes (triangles),

and 5 familial hypercholesterolemic homozygotes (diamonds) after a 40-g fat meal with 50,000 U vitamin A. For each group the levels at each time point were averaged. Bars represent the standard errors of the means. 


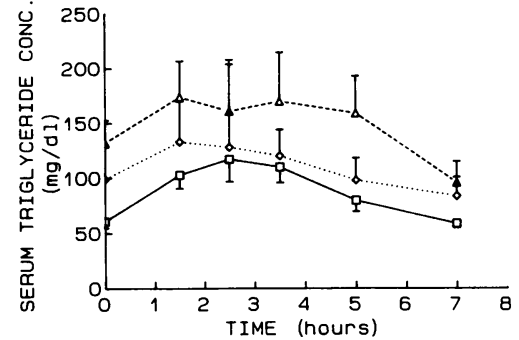

terolemic homozygotes (diamonds) after a 40-g fat me group the levels at each time point were averaged. Bars represent the standard errors of the means.

clearance in the FHH patients was masked by impaired vitamin A absorption. Several lines of evidence argue against this, however. Severe malabsorption of fat was not present as the magnitude of postprandial lipemia was similar in $\mathrm{FHH}$ patients and in the other two groups, and none of the subjects had gastrointestinal symptoms of fat malabsorption (such as diarrhea). Alternatively, it might be argued that fat absorption was delayed rather than decreased in the FHH patients. This possibility seems equally unlikely, as the postprandial excursion of serum triglyceride began promptly in the FHH group and returned to baseline values within $7 \mathrm{~h}$. A specific defect in vitamin A absorption secondary to LDL receptor deficiency is also improbable, since serum vitamin $\mathrm{A}$ concentrations are normal in FHH patients (30), and no symptoms of vitamin A deficiency developed in the present group despite fortnightly plasma exchange.

The 7-h time course of our study is sufficient to detect the type of remnant accumulation that would occur if the LDL receptor played a significant role in chylomicron remnant clearance from the plasma. Studies by Havel (31), using radiolabeled apo B48, by Cortner (32), using vitamin A oral fat tolerance tests, and by Berr (19), using reinjection of vitamin A-labeled chylomicrons, have all shown that the half-life of chylomicron remnants in normal plasma is $15-30 \mathrm{~min}$. If it is assumed that the postprandial rise in plasma triglyceride concentrations represents diet-derived fats (33), and if plasma retinyl palmitate is born mainly by chylomicron remnants, the postprandial vitamin A excursion should follow the plasma triglyceride curve with a lag of less than $60 \mathrm{~min}$, given normal remnant clearance (this was the case in our normal subjects). Conversely, under conditions where triglyceride clearance is normal but chylomicron remnant clearance is impaired, the vitamin A excursion would show prompt and progressive divergence from the triglyceride curve as remnants accumulated. As dietary fat absorption slowed, input into the remnant pool would cease, and the retinyl ester curve would plateau, reflecting the presence of long-lived remnants in the circulation. This behavior was clearly shown by the apo E2/2 homozygotes in our study, in which remnant particles were detected at $7 \mathrm{~h}$ by both electrophoretic analysis and by density gradient ultracentrifugation. In the FHH patients we studied, fat absorption was maximum $\sim 1.5 \mathrm{~h}$ after the meal, as indicated by plasma triglyceride concentrations. In the critical first $5 \mathrm{~h}$ when fat absorption occurred, the retinyl ester responses of the FHH patients were very similar to those of the normal subjects. Impairment of chylomicron remnant clearance would have been apparent at the time when the rate of input of remnants into the circulation was greatest. Thus, Weintraub et al. (34) detected the greatest difference between the chylomicron remnant retinyl palmitate concentrations of normolipidemic E2/3 subjects (who have mildly impaired clearance) and E3/3 subjects at $\sim 3 \mathrm{~h}$ after the meal.

The main deviation from normal in our FHH subjects was the progressive accumulation of retinyl palmitate in the LDL flotation range, which accounted for $40 \%$ of their serum retinyl palmitate at $7 \mathrm{~h}$. This accounted for more than $70 \%$ of the discrepancy between RP levels (in serum or in the remnant fraction) of the FHH and normal subjects at this time point. The increased LDL-RP during vitamin A fat tolerance tests, which has been reported previously $(19,20)$, is believed to

Table II. Maximum, High Affinity ${ }^{125}$ I- $\beta V L D L$ and ${ }^{125}$ I-LDL Degradation Rates by Cultured Upregulated Fibroblasts from the FHH Subjects

\begin{tabular}{|c|c|c|c|c|c|c|c|}
\hline \multirow[b]{2}{*}{ Subject } & \multicolumn{5}{|c|}{$\begin{array}{l}\beta \mathrm{VLDL} \text { degradation rates } \\
(\% \text { normal })\end{array}$} & \multicolumn{2}{|c|}{$\begin{array}{l}\text { LDL degradation rates } \\
\text { (\% normal) }\end{array}$} \\
\hline & Exp. 1 & Exp. 2 & Exp. 3 & $A v . \pm S D$ & Exp. 3 & Exp. 1 & Exp. 2 \\
\hline & & & & & $\mathrm{K}_{d} \mu g / m l$ & & \\
\hline S.A. & 26 & 34 & 32 & $31 \pm 4$ & $1.0 \pm 1.0$ & 19 & 27 \\
\hline R.I. & 8 & 14 & 12 & $11 \pm 3$ & $1.3 \pm 0.7$ & $<1$ & $<1$ \\
\hline C.F. & 3 & ND & 16 & 9.5 & $3.0 \pm 2.0$ & 4 & ND \\
\hline A.C. & 30 & 42 & 72 & $48 \pm 21$ & $4.4 \pm 1.1$ & 26 & 35 \\
\hline G.V. & 13 & 46 & 14 & $24 \pm 18$ & $1.9 \pm 0.3$ & 6 & 19 \\
\hline
\end{tabular}

High-affinity values, which represent the difference between values obtained in the absence and presence of the appropriate cold ligand, are presented in experiments 1 and 2 . In experiment 3 , total values at various ${ }^{125} \mathrm{I}-\beta \mathrm{VLDL}$ concentrations were fitted by nonlinear regression using a computer program (Enzfitter; Elsevier Biosoft), assuming binding to a single site and nonspecific binding, so that $K_{d}$ and maximum specific values could be calculated. The $K_{\mathrm{d}}$ values presented are the means \pm the estimated standard error of each curve, and the maximum values for ${ }^{125} \mathrm{I}-\beta \mathrm{VLDL}$ degradation rates are presented as a percentage of maximum specific values obtained in two normal cell lines analyzed in parallel in each experiment. The $K_{d}$ represents the ${ }^{125} \mathrm{I}-\beta \mathrm{VLDL}$ concentrations at half the maximum ${ }^{125} \mathrm{I}-\beta \mathrm{VLDL}$ degradation rates. The $K_{\mathrm{d}}$ 's of the fibroblasts from the two normal subjects in experiment 3 were $1.04 \pm 0.4$ and $0.93 \pm 0.04 \mu \mathrm{g} / \mathrm{ml}{ }^{125} \mathrm{I}-\beta \mathrm{VLDL}$, and the maximum receptor-mediated degradation rates for the two normals were $2,029 \pm 415$ and $1,721 \pm 2 \mathrm{ng}{ }^{125} \mathrm{I}-\beta \mathrm{VLDL}$ degraded per $\mathrm{mg}$ cell protein/4 h, respectively. ND, not done. 


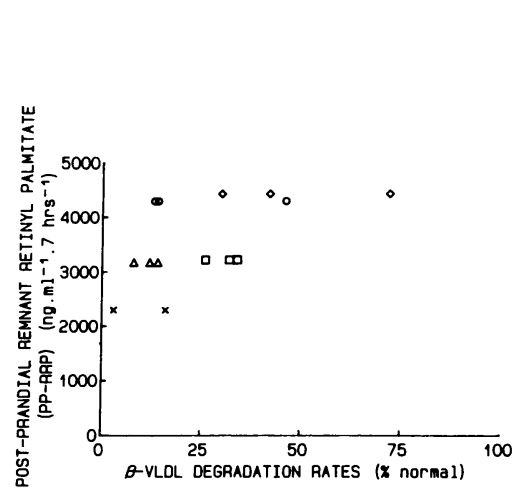

reflect RP transfer (35), and may account for up to $10 \%$ of serum RP in normal subjects. Since lipid transfer is partly determined by the relative proportions of donor and acceptor particles (36), it seems likely that increased quantities of RP were transferred to the enlarged LDL pool in FHH subjects. Alternatively, one could postulate that the RP in the LDL fraction represented a population of abnormal B48 containing chylomicron remnants, which did not have beta-migrating electrophoretic properties. Such particles would have had to be long-lived and would have had to appear later than the chylomicron remnants of normal subjects, since the LDL-RP levels in the FHH subjects were similar to the normal levels $2.5 \mathrm{~h}$ postprandially and accumulated over the following $4.5 \mathrm{~h}$. These particles were unlikely to have been derived from longlived, poorly cleared IDL-sized chylomicron remnants, which had been so extensively lipolyzed that they attained LDL flotation characteristics, since our RP experiments, lipoprotein electrophoretograms, and density gradient studies showed no abnormal accumulation of IDL-sized remnants in the FHH subjects. Apo B48 has not been found in fasting LDL from FHH patients $(37,38)$, and Gabelli et al. have reported rapid catabolism of radiolabeled apo B48-enriched VLDL ( $d$ $<1.006 \mathrm{~g} / \mathrm{ml}$ ) injected into FH homozygotes with no abnormal conversion into IDL- and LDL-sized particles (39). Therefore, the RP detected in the LDL fractions of the FHH patients can safely be assumed to have been the result of transfer of RP from chylomicron remnants to the large acceptor LDL pool found in such individuals.

The delayed chylomicron remnant clearance in the apo E2/2 phenotype, which results from poor recognition of the apo E2 isoform by hepatic receptors, is indicative of an important degree of control exerted on overall remnant clearance by a receptor-mediated step involving apo E3 and/or apo E4 as ligands. If the LDL receptor were the sole or major route for the clearance of chylomicron remnants from the plasma, one would expect abnormal remnant accumulation in the $\mathrm{FHH}$ patients. Furthermore, the availability of $\mathrm{FHH}$ subjects whose fibroblasts tested in vitro displayed a range of $\beta$ VLDL- and LDL-degrading capacities, made possible a crude but effective demonstration of control analysis (Kaczer and Porteous, 40) in that we could show how increasing degrees of impairment of LDL-receptor function did not correlate with progressive inhibition of chylomicron remnant clearance. The clearance pathway must therefore involve another apo $\mathrm{E}$ recognizing receptor, the activity of which has a significant effect on the clearance of remnants from the circulation.
This study has measured the clearance from the plasma, but not the uptake into the liver of chylomicron remnants. The conclusion that LDL receptors do not play a significant role in chylomicron remnant clearance from the plasma, does not preclude the suggestion that low numbers of LDL receptors may be sufficient to endocytose remnant particles, which have been "precleared" from the circulation by high capacity binding sites in hepatic sinusoids, possibly of a glycosaminoglycan nature (1).

In summary, the results of this study indicate that chylomicron remnant clearance shows normal kinetic features in a set of FHH subjects with varying degrees of LDL receptor deficiency, but is greatly impaired in normolipidemic apo E2/2 homozygotes. Interpretation of these findings in the light of metabolic control analysis suggests that chylomicron remnants are initially removed from the circulation mainly by receptors that recognize apo $\mathrm{E}$ but are genetically distinct from LDL receptors.

\section{Acknowledgments}

Felicity Leisegang, Rolene Liebenberg, and Majiet Hargey are thanked for technical assistance.

Financial support from the South African Medical Research Council, the University of Cape Town, the Guy Elliott Fellowship which supported Dr. Rubinsztein, and the South African Sugar Association which supported Dr. Cohen, is acknowledged.

\section{References}

1. Mahley, R. W., D. Y. Hui, T. L. Innerarity, and U. Beisiegel. 1989. Chylomicron remnant metabolism: role of hepatic lipoprotein receptors in mediating uptake. Arteriosclerosis. 19(Suppl):I-14-I-18.

2. Sherrill, B. C., T. L. Innerarity, and R. M. Mahley. 1980. Rapid hepatic clearance of the canine lipoproteins containing only the $\mathrm{E}$ apoprotein by a high affinity receptor. J. Biol. Chem. 255:1804-1807.

3. Windler, E., Y. Chao, and R. J. Havel. 1980. Determinants of hepatic uptake of triglyceride-rich lipoproteins and their remnants in the rat. J. Biol. Chem. 255:5475-5480.

4. Arbeeny, C. M., and V. A. Rifici. 1984. The uptake of chylomicron remnants and very low density lipoprotein remnants by the perfused rat liver. J. Biol. Chem. 259:9662-9666.

5. Cooper, A. D., S. V. Erickson, R. Nutik, and M. A. Shrewsbury. 1982. Characterization of chylomicron remnant binding to rat liver membranes. J. Lipid Res. 23:42-52.

6. Hui, D. Y., T. L. Innerarity, R. W. Milne, Y. L. Marcel, and R. W. Mahley. 1984. Binding of chylomicron remnants and $\beta$-very low density lipoproteins to hepatic and extra-hepatic lipoprotein receptors. J. Biol. Chem. 259:15060-15068.

7. Francke, U., M. S. Brown, and J. L. Goldstein. 1984. Assignment of the human gene for the low density lipoprotein receptor to chromosome 19: synteny of a receptor, a ligand and a genetic disease. Proc. Natl. Acad. Sci. USA. 81:2826-2830.

8. Brown, M. S., and J. L. Goldstein. 1983. Lipoprotein receptors in the liver. Control signals for plasma cholesterol traffic. J. Clin. Invest. 72:743-747.

9. Windler, E. E. T., J. Greene, W. H. Daerr, and H. Green. 1988. Binding of rat chylomicrons to the hepatic low-density lipoprotein receptor and its role in remnant removal. Biochem. J. 252:553-561.

10. Nagata, Y., J. Chen, and A. D. Cooper. 1988. Role of low density lipoprotein receptor-dependent and -independent sites in binding and uptake of chylomicron remnants in rat liver. J. Biol. Chem. 263:15151-15158. 
11. Kita, T., J. L. Goldstein, M. S. Brown, Y. Watanabe, C. A. Hornick, and R. J. Havel. 1982. Hepatic uptake of chylomicron remnants in WHHL rabbits: a mechanism genetically distinct from the low density lipoprotein receptor. Proc. Natl. Acad. Sci. USA. 79:36233627.

12. Goldstein, J. L., and M. S. Brown. 1983. Familial hypercholesterolemia. In The Metabolic Basis of Inherited Disease. J. B. Stanbury, J. B. Wyngaarden, D. S. Frederickson, J. L. Goldstein, and M. S. Brown, editors. 5th ed. McGraw-Hill Inc., New York. 672-712.

13. Hobbs, H. H., M. S. Brown, J. L. Goldstein, and D. W. Russell. 1986. Deletion of exon encoding cysteine-rich repeat of low density lipoprotein receptor alters its binding specificity in a subject with familial hypercholesterolemia. J. Biol. Chem. 261:13114-13120.

14. Wernette-Hammond, M. E., Z. Garcia, K. S. Arnold, and T. L. Innerarity. 1989. $\beta$-very low density lipoprotein uptake in cultured fibroblasts and smooth muscle cells from Watanabe heritable hyperlipidemic rabbits. Arteriosclerosis. 9:501-510.

15. Mahley, R. W., and T. L. Innerarity. 1983. Lipoprotein receptors and cholesterol homeostasis. Biochim. Biophys. Acta. 737:197222.

16. Hazzard, W. R., and E. L. Bierman. 1976. Delayed clearance of chylomicron remnants following vitamin A-containing oral fat loads in broad-B disease (type III hyperlipoproteinemia). Metab. Clin. Exp. 25:777-801.

17. Goodman, D. S., R. Blomstrand, B. Werner, H. S. Huang, and T. Shiratori. 1966. The intestinal absorption and metabolism of vita$\min A$ and $\beta$-carotene in man. J. Clin. Invest. 45:1615-1623.

18. Goodman, D. S. 1980. Vitamin A metabolism. Fed. Proc. 39:2716-2722.

19. Berr, F., and F. Kern. 1984. Plasma clearance of chylomicrons labelled with retinyl palmitate in healthy human subjects. J. Lipid Res. 25:805-812.

20. Wilson, D. E., I.-F. Chan, and M. Ball. 1983. Plasma lipoprotein retinoids after vitamin A feeding in normal man: minimal appearance of retinyl esters among low-density lipoproteins. Metab. Clin. Exp. 32:514-517.

21. Leitersdorf, E., D. R. van der Westhuyzen, G. A. Coetzee, and H. H. Hobbs. 1989. Two common low density lipoprotein receptor gene mutations cause familial hypercholesterolemia in Afrikaners. $J$. Clin. Invest. 84:954-961.

22. Fourie, A. M., G. A. Coetzee, W. Gevers, and D. R. van der Westhuyzen. 1988. Two mutant low density lipoprotein receptors in Afrikaners slowly processed to surface forms exhibiting rapid degradation or functional heterogeneity. Biochem. J. 255:411-415.

23. Grundy, S. M., and H. Y. I. Mok. 1976. Chylomicron clearance in normal and hyperlipidemic man. Metab. Clin. Exp. 25:1225-1239.

24. Weintraub, M. S., S. Eisenberg, and J. L. Breslow. 1987. Different patterns of postprandial lipoprotein metabolism in normal, Type IIa, Type III, and Type IV hyperlipidemic individuals. Effects of treatment with cholestyramine and gemfibrozil. J. Clin. Invest. 79:1110-1119.

25. Huang, H. S., and D. S. Goodman. 1965. Vitamin A and carotenoids. 1. Intestinal absorbtion and metabolism of ${ }^{14} \mathrm{C}$-labeled vitamin A-alcohol and beta carotene in the rat. J. Biol. Chem. 240:2839-2844.

26. Tollaksen, S. L., N. L. Anderson, and N. G. Anderson. Operation of the Iso-Dalt System. 1981. 6th ed. Argonne National Laboratories, Argonne, IL.

27. Aulinskas, T. H., D. R. van der Westhuyzen, and G. A. Coetzee. 1983. Ascorbate increases the number of low density lipoprotein receptors in cultured arterial smooth muscle cells. Arteriosclerosis. 47:159-171.

28. Kovanen, P. T., M. S. Brown, S. K. Basu, D. W. Bilheimer, and J. L. Goldstein. 1981. Saturation and suppression of hepatic lipoprotein receptors: a mechanism for the hypercholesterolemia of cholesterol-fed rabbits. Proc. Natl. Acad. Sci. USA. 78:1396-1400.

29. Bierman, E. L., O. Stein, and Y. Stein. 1974. Lipoprotein uptake and metabolism by rat aortic smooth muscle cells in tissue culture. Circ. Res. 35:136-150.

30. Armstrong, V. W., D. Niedmann, T. Eisenhauer, G. Jannig, H. Wagner, P. Schuff-Werner, and D. Seidel. 1988. Acute and long-term effects of low-density lipoprotein apheresis for the serum concentrations of vitamins E and A. Klin. Wochenschr. 66:123-128.

31. Stalenhoef, A. F. H., M. J. Malloy, J. P. Kane, and R. J. Havel. 1984. Metabolism of apoproteins B-48 and B-100 of triglyceride-rich lipoproteins in normal and lipoprotein lipase-deficient humans. Proc. Natl. Acad. Sci. USA. 81:1839-1843.

32. Cortner, J. A., P. M. Coates, N.-A. Le, D. R. Cryer, M. C. Ragii, A. Faulkner, and T. Langer. 1987. Kinetics of chylomicron remnant clearance in normal and in hyperlipoproteinemic subjects. J. Lipid Res. 28:195-206.

33. Cohen, J. C. 1989. Chylomicron triglyceride clearance: comparison of three assessment methods. Am. J. Clin. Nutr. 49:306-313.

34. Weintraub, M. S., S. Eisenberg, and J. L. Breslow. 1987. Dietary fat clearance in normal subjects is regulated by genetic variation in apolipoprotein E. J. Clin. Invest. 80:1571-1577.

35. Zilversmit, D. B., R. E. Morton, L. B. Hughes, and K. H. Thompson. 1982. Exchange of retinyl and cholesteryl esters between lipoproteins of rabbit plasma. Biochim. Biophys. Acta. 712:88-93.

36. Tall, A., D. Sammet, and E. Granot. 1986. Mechanisms of enhanced cholesteryl ester transfer from high density lipoproteins to apolipoprotein B-containing lipoproteins during alimentary lipemia. J. Clin. Invest. 77:1163-1172.

37. Patsch, W., R. Ostlund, I. Kvisk, R. Levy, and G. Schonfeld. 1982. Characterization of lipoprotein in a kindred with familial hypercholesterolemia. J. Lipid Res. 23:1196-1205.

38. Meng, M. S., R. E. Gregg, E. J. Schaefer, J. M. Hoeg, and H. B. Brewer, Jr. 1983. Presence of two forms of apolipoprotein B in patients with dyslipoproteinemia. J. Lipid Res. 24:803-809.

39. Gabelli, C., R. E. Gregg, L. A. Zech, J. M. Hoeg, H. B. Brewer, Jr. 1984. Apo B-48 catabolism in normal and homozygous Familial Hypercholesterolemia individuals. Clin. Res. 32(2):166a. (Abstr.)

40. Kaczer, H., and J. W. Porteous. 1987. Control of metabolism: what do we have to measure? Trends Biochem. Sci. 12:5-14. 